\title{
Nephroprotective Hepatoprotective Potential and Antioxidant Role of Carob Pods (Cerotonia siliqua L.) against Carbon Tetrachloride-induced Toxicity in Rats
}

\author{
Huseyin Suzek ${ }^{1}$, Ismail Celik ${ }^{2 *}$, Abdulahad Dogan ${ }^{3}$ \\ ${ }^{1}$ Deparment of Nursing, Health High School, Mugla Sıtkı Kocman University, Muğla, TURKEY. \\ 2Department of Molecular Biology and Genetic, Science Faculty, Yuzuncu Yil University, Van, TURKEY. \\ ${ }^{3}$ Department of Biochemistry, Faculty of Pharmacy, Yuzuncu Yil University, Van, TURKEY.
}

\begin{abstract}
Objective: The aims of current study are the evaluation of the protective effect and antioxidant role of carob pods against carbon tetrachloride $\left(\mathrm{CCl}_{4}\right)$-induced oxidative stress, hepatotoxicity and nephropathy. Material and Methods: The present experiment was designed as I (control), II $\left(0.5 \mathrm{ml} / \mathrm{kg} \mathrm{CCl}\right.$ ), III (\%10 CP), IV $\left(\mathrm{CCl}_{4} 0.5 \mathrm{ml} / \mathrm{kg}+\% 10\right.$ CP) groups. While rats in group I and III were fed with a diet without $\mathrm{CCl}_{4}$, II, and IV groups received twice $0.5 \mathrm{ml} / \mathrm{kg} /$ week, where IV group additionally received \%10 CP supplementation for 50 days. The protective roles and antioxidant activity of the CP supplementation feed against $\mathrm{CCl}_{4}$-induced oxidative stress and toxicity were evaluated by histopathological changes, measuring hepatic and renal damage biomarkers (HRDB), antioxidant defence system constituents (ADSC) and malondialdehyde (MDA) parameters in the erythrocyte, liver, brain, kidney and spleen tissues of rats. Results: According to the results, the biochemical analysis showed a considerable increase in the serum AST (aspartate aminotransferase), ALT (alanin aminotransferase), GGT (gamma glutamyl transpeptidase) and LDH (lactate dehydrogenase) enzymes, creatinine and urea, and decrease in the group II as compared to that of I group. On contrary, such parameters were decreased in IV group as compared to that of group II. In addition, the results showed that CP supplementation diet restored the $\mathrm{CCl}_{4}$ induced MDA (malondialdehyde) and ADSC towards to control. The hepatoprotection of $\mathrm{CP}$ is further substantiated by the almost normal histological findings in IV group against degenerative changes in II group. Protective effects by CP are further substantiated by the almost normal HRDB for kidney and liver in IV treated group as against degenerative changes in the II treated rats. Conclusion: The results indicated that $\mathrm{CP}$ could be as an important as diet-derived antioxidants in preventing oxidative damage in the tissues by reducing the MDA or inhibiting the production of $\mathrm{CCl}_{4}$-induced free radicals and liver and kidney destruction.
\end{abstract}

Key words: Carbon tetrachloride, Carob pods, Protective potential, Antioxidant role.

\section{INTRODUCTION}

There is a growing interest of natural products in human diet, both due to the possible negative effects of synthetic food additives on human health and the increased consumer perception of this problem in recent years. ${ }^{1}$ Epidemiological studies consistently show that increased consumption of plant-based, antioxidant-rich foods, i.e., fruits, vegetables, whole grains, and nuts, is associated with the reduced risk for several chronic diseases. ${ }^{2}$ Biomolecules from plants have attracted a great deal of attention, mainly concentrated on their role in preventing diseases. In addition, epidemiological studies have consistently shown that there is a clear significant positive association between intake of these
Submission Date: 30-08-2016; Revision Date: 17-11-2016; Accepted Date: 23-11-2016

DOI: 10.5530/ijper.51.2.37 Correspondence: Ismail Celik, Yuzuncu Yil University, Science Faculty Department of Molecular Biology and Genetic 65080 Van, TURKEY.

Fax: +90.432 .2251188$ TIf: $+90.432 .2251704 / 2278$ E-mail: icelik65@gmail.com, icelik@yyu.edu.tr

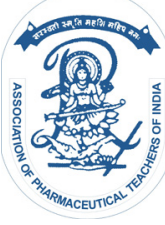

www.ijper.org 
natural products and reduced rate of heart disease mortalities, common cancers and other degenerative diseases. ${ }^{3}$ The carob tree, an evergreen plant, is generally grown at Mediterranean region. Per year, about 13500 Tons CP are produced in Turkey. ${ }^{4}$ The carob includes pod and seed. Carob pods have been generally consumed as human food and animal feed. The importance of carob arises from its seed. Nowadays, carob seeds have been paid attention on and they have acted an important role economically since they are used as food additives, in pharmaceutical and cosmetic industries. ${ }^{5-7}$ In vitro antioxidant activities of $\mathrm{CP}$ have been examined by $\mathrm{Fe}^{+3}$ reducing, radical scavenging power activity ${ }^{8}$ and by oxidation of linoleic acid. ${ }^{9}$ Carob seeds are a particularly rich source of complex polymers of flavonoids such as proanthocyanidin, ellagitannin, and gallotannin. These phytochemicals have been used in medicine for its pharmacological properties against numerous diseases and have free radical scavenging activities. ${ }^{10}$ Further, it was concluded that carob seeds has a hepatoprotective effect and antioxidant capacity in rats with ethanol toxicity, probably acting by promoting the antioxidative defense systems. ${ }^{1}$ Carob pulp increases the blood glucose values after digestion in healthy subjects. Specially, it has reported that $5 \mathrm{~h}$ after consumption of $20 \mathrm{~g}$ carob flour decreased serum triacylglycerol levels. ${ }^{11}$ In addition, Carob fibers extract inhibiting DNA synthesis inhibits cell proliferation (in vitro) by adenoma suppressing to adenocarsinoma. ${ }^{12}$

As far as our literature survey could ascertain, little studies have so far been reported on the hepatoprotective and nephroprotective role and antioxidant capacity of the $\mathrm{CP}$ supplementation. The objective of this study was to determine healthful potentials of $\mathrm{CP}$ against $\mathrm{CCl}_{4}^{-}$ induced oxidative stress and toxicity by evaluating their in vivo hepatoprotective and nephroprotective role and antioxidant role. Thus, in the present study, it was extensively studied the antioxidant activity chemopreventive of CP using in vivo models. For this aim, the treatment of CP was done orally as food containing CP 10\% because the effect of the functional plant represents a well characterized in nutrition and widely used as consumption by human in our country Turkish folk medicine. The serum HRDB such as AST (aspartate aminotransferase), ALT (alanin aminotransferase) GGT (gamma glutamyl transpeptidase) LDH (lactate dehydrogenase) TP (total protein) TC (total cholesterol) and histopathological changes were chosen due to their importance as index of hepatotoxicity and nephropathy. In addition, It was determined the effects of carbon tetrachloride $\left(\mathrm{CCl}_{4}\right)$ and CP supplementation on some phase II detoxification ADS (antioxidant defence systems) such as GSH (reduced glutathione), GR (glutathione reductase), SOD (superoxide dismutase), GST (glutathione $S$-transferase), CAT (catalase), GPx (glutathione peroxidise) and MDA (malondialdehyde) parameters in the erythrocyte, liver, brain, kidney and spleen tissues of rats 50 days during experiment.

\section{MATERIALS AND METHODS}

\section{Chemicals}

Thiobarbituric acid (TBA), butylated hydroxytoluene (BHT), trichloroacetic acid (TCA), ethylenediaminetetraacetic acid (EDTA), reduced glutathione (GSH), metphosphoric acid, 5,5' dithiobis-(2-nitrobenzoic acid) (DTNB), trihydroxymethyl aminomethane (Tris), 1-chloro-2,4-dinitrobenzene (CDNB), oxidized glutathione (GSSG), $\beta$-Nicotinamide adenine dinucleotide phosphate (NADPH), potassium dihydrogen phosphate $\left(\mathrm{KH}_{2} \mathrm{PO}_{4}\right)$ and sodium chloride $(\mathrm{NaCl})$ of technical grade used in this study were supplied by Sigma Chemical Co. (St. Louis, MO, USA). Kits for antioxidant enzymes analysis were supplied by Randox Laboratories ltd.

\section{Animals}

Rats (Wistar albino) with an average weighing 200-300 g were provided from the Experimental Animal Research Centre, Yuzuncu Yil University, and were housed in 4 groups, each group containing 6 rats. The animals were housed at $20^{\circ} \pm 2^{\circ} \mathrm{C}$ in a daily light/dark $(\sim 16 / 8)$ cycle. All animals were fed a group wheat-soybean-meal-based diet and water ad libitum in stainless cages, and received humane care according to the criteria outlined in the 'Guide for the Care and Use of Laboratory Animals' prepared by the National Academy of Science and published by the National Institutes of Health. The ethic regulations were followed in accordance with national and institutional guidelines for the protection of animal welfare during experiments. This study was approved by The Ethic Committee of the Yuzuncu Yil University.

\section{Preparation of food}

CP (Cerotonia siliqua L.) was provided from a tree local producer in Fethiye, Köycegiz, and a major CP producing province of Muğla-Turkey. The natural CP is a seller local market. CP was ground into powder and then the amount of powdered CP was adjusted to $10 \%$ of the rat food.

\section{Experimental design}

The rats were randomly divided into four groups each containing six rats. 
Group I (Control): the rats received tab water and fed with standard pellet diet as ad libitum.

Group II $\left(\mathrm{CCl}_{4}\right)$ : the rats received $0.5 \mathrm{ml} \mathrm{CCl}_{4} / \mathrm{kg}$ rat weight intraperitonally and fed with standard pellet diet as ad libitum. Dose of $\mathrm{CCl}_{4}$ was selected on the basis of a $0.5 \mathrm{ml} \mathrm{CCl} / \mathrm{kg}$ rat weight diluted in olive oil (1:1 dilution) intraperitonally injection twice per week concentration at which caused oxidative stress and hepatotoxicity administered. ${ }^{13}$

Group III (10\% CP): the rats received tab water and fed with $10 \%$ CP containing diet supplementation.

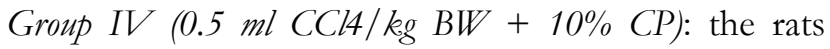
received $0.5 \mathrm{ml} \mathrm{CCl}_{4} / \mathrm{kg}$ rat weight intraperitonally injection twice per week and fed with $10 \%$ CP containing diet supplementation.

\section{Preparation of tissues supernatant and erythrocyte pellets}

At the end of the 50 days experiments, the rats were anesthetized by injection of ketamine $(5 \mathrm{mg} / 100 \mathrm{~g}$ body weight) intraperitonally. The blood samples were obtained from a cardiac puncture using syringe for the determination of serum HRDB levels and biochemical analysis. The serum samples were obtained by centrifuging blood samples at $4000 \mathrm{xg}$ for $15 \mathrm{~min}$ at $4^{\circ} \mathrm{C}$, and enzyme levels were measured in these serum samples. For biochemical analysis, blood samples were immediately put into silicon disposable glass tubes with EDTA as an anticoagulant and were centrifuged at 4000xg for $15 \mathrm{~min}$ at $4^{\circ} \mathrm{C}$ and erythrocyte pellets were obtained. Then, the pellets were washed tree times with physiological saline $(0.9 \% \mathrm{NaCl})$.

The tissues (brain, kidney, spleen and liver) were dissected and put in Petri dishes. After washing the tissues with physiological saline $(0.9 \% \mathrm{NaCl})$, samples were taken and kept at $-78^{\circ} \mathrm{C}$ during the analysis. The tissues were homogenized for $5 \mathrm{~min}$. in $50 \mathrm{mM}$ ice-cold $\mathrm{KH}_{2} \mathrm{PO}_{4}$ solution $(1: 5 \mathrm{w} / \mathrm{v})$ using stainless steel probe homogenizer $(20 \mathrm{KHz}$ frequency ultrasonic, Jencons Scientific Co.) for $5 \mathrm{~min}$. and then centrifuged at $7000 \mathrm{xg}$ for $15 \mathrm{~min}$. All processes were carried out at $4^{\circ} \mathrm{C}$. Supernatants and erythrocyte pellets were used to determine ADS constituents and MDA contents. ${ }^{14,15,16}$

\section{Biochemical analysis}

The erythrocyte and tissues MDA (Malondialdehyde) concentration were determined using the method described by Jain et al. ${ }^{36}$ based on TBA reactivity. The erythrocyte and tissues GSH (reduced glutathione) concentration was measured using the method described by Beutler et al. ${ }^{17}$ GST (glutathione $S$-transferase) was assayed by following the conjugation of glutathione with 1-chloro-2,4-dinitrobenzene (CDNB) at $340 \mathrm{~nm}$ as described by Mannervik and Guthenberg. ${ }^{18}$ GR (glutathione reductase) activity was assayed according to Carlberg and Mannervik ${ }^{19}$ as the decrease in absorbance of NADPH at $340 \mathrm{~nm}$. GPx (glutathione peroxidise) activity was assayed according to Paglia and Valentine ${ }^{20}$ based on that the GPx catalyses the oxidation of GSH by cumene hydroperoxide. SOD (superoxide dismutase) activity was measured at $505 \mathrm{~nm}$ by calculating inhibition percentage of formazan dye formation. ${ }^{21}$ CAT (catalase) activity was determined using the method described by Aebi ${ }^{22}$ based on that of the rate of $\mathrm{H}_{2} \mathrm{O}_{2}$ consumption and as the decrease in absorbance at $240 \mathrm{~nm}$.

\section{Measurement of enzyme levels}

Hepatic and renal damage biomarkers levels such as such as AST, ALT, GGT, LDH, total cholesterol (TC), total protein (TP) creatinine and urea levels were measured by an auto analyzer (COBAS 8000/ROCHE/ Germany/Serial No 1296-08) using the Roche kits.

\section{Analysis of data}

All data were expressed as mean \pm standard deviation (SD). The statistical analyses were made using the Minitab 13 for windows packet program. Means and Standard deviations were calculated according to the standard methods for all parameters. One-way analysis of variance (ANOVA) statistical test was used to determine the differences between means of the experimental groups accepting the significance level at $\mathrm{p} \leq 0.05$.

\section{Histopathological examination}

Tissue samples from organs were collected in 10\% neutralized formaldehyde after sacrification. After fixation, samples were dehydrated in alcohol, cleared in xylene and embedded in paraffin wax. Sections were cut at $5 \mu \mathrm{m}$ and stained with haematoxylin and eosin (Thermo Shandon, 15275, USA). Microscopically, degenerations in livers and kidneys were graded. Hepatocellular degeneration in livers as follows; Slight (degree 1): Mild hepatocellular swelling due to hydropic degeneration and fatty changes only in centrilobular areas. Moderate (degree 2): Clear hepatocellular swelling in both centrilobular and midzonal areas. Severe (degree 3): Diffuse and severe hepatocellular swelling, cytoplasmic paleness and rupture. ${ }^{23}$

\section{RESULTS}

Effects of carob pods supplementation on body
weights and hepatic and renal damage biomarkers

Hepatic and renal damage biomarkers levels such as AST, ALT, GGT, LDH, TC, TP, creatinine and urea levels as 
well as body weight of control, $\mathrm{CCl}_{4}, \mathrm{CP}$-treated and $\mathrm{CCl}_{4}+\mathrm{CP}$-treated groups rats were summarized in Table 1 . The dosage of $\mathrm{CCl}_{4}$ and $\mathrm{CP}$ supplementation did not show any mortality in all groups during experimental period. Body weights of the rats increased in all groups. Present results showed that levels of hepatic and renal damage biomarkers except for TC and TP were markedly elevated in $\mathrm{CCl}_{4}$-treated group in comparison to control group. By contrast, levels of these biomarkers were prominently dropped in $\mathrm{CCl}_{4}+\mathrm{CP}$-treated group with respect to $\mathrm{CCl}_{4}$-treated group. In addition, there was a significant difference in GGT and LDH levels between control and $\mathrm{CCl}_{4}+\mathrm{CP}$-treated groups (Table 1).

\section{Effects of carob pods supplementation on antioxidant defence system constituents and malondialdehyde}

Following the treatment of experimental groups, the effect of $\mathrm{CCl}_{4}$ and the $\mathrm{CP}$ (carob pods) supplemented diet on oxidative stress were evaluated as ADS (antioxidant defense system) constituents and MDA content of blood and erythrocyte, liver, brain, kidney and spleen tissues of rats. The study results showed that $\mathrm{CCl}_{4}$ significantly increased MDA content of the tissues in comparison to control whereas, MDA contents of the tissues significantly decreased in the dried CP supplementation group in comparison to $\mathrm{CCl}_{4}$ group. On the other hand, the results of experiment showed that the treatment of rats with $\mathrm{CCl}_{4}$ and $\mathrm{CCl}_{4}+\mathrm{CP}$ supplementation caused changes in ADS constituents of the erythrocyte, liver, brain, kidney and spleen tissues in comparison to those of control rats. Namely, while $\mathrm{CCl}_{4}$ caused fluctuation in ADS constituents level as a result of oxidative stress condition in the rats, CP supplementation diet restored the $\mathrm{CCl}_{4}$-induced ADS constituents towards to control (Table 2).

\section{Microscopic Findings}

With regard to liver histopathological changes, the livers of the rats from control and 10\% dried CP group had no noticeable histological changes (Figure 1,3). Evident histopathological changes were consistently observed in livers of all the rats from $\mathrm{CCl}_{4}$ and $\mathrm{CCl}_{4}+$ the functional food treated group. In the second group of rats with $\mathrm{CCl}_{4}$ group, severe hydropic degeneration in the liver in the portal area, a small number of necrotic cells and intra-hepatic cholestasis was found. In addition, the portal area region toward setral fibrosis in the group II was observed (Figure 2). These findings in the group IV are similar to group II findings (Figure 4).

\begin{tabular}{|c|c|c|c|c|c|}
\hline \multicolumn{5}{|c|}{ Table 1: Effect of CCI and carob pods on serum liver and kidney damage biomarker and body } \\
weight of rats
\end{tabular}

Each value is the mean \pm SD of 6 animals per group (One way ANOVA).

*: Significantly different from the beginning.

a: Significantly different from control group.

b: Significantly different from $\mathrm{CCl}_{4}$ group. 
Table 2: Determination antioxidant capacity of carob pods against $\mathrm{CCl}_{4}$-induced oxidative stress

\begin{tabular}{|c|c|c|c|c|c|}
\hline Tissue & Parameters & Control & $\mathrm{CCl}_{4}$ & CP & $\mathrm{CP}+\mathrm{CCl}_{4}$ \\
\hline \multirow{7}{*}{ 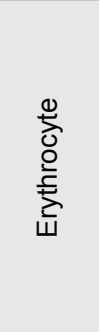 } & GSH (mg/ ml) & $75.21 \pm 0.13$ & $72.88^{a} \pm 0.42$ & $75.43 \pm 0.35$ & $75.34^{b} \pm 0.34$ \\
\hline & MDA (nmol/ml) & $1.41 \pm 0.20$ & $2.92^{\mathrm{a}} \pm 0.52$ & $1.40 \pm 0.29$ & $1.96^{\mathrm{a}, \mathrm{b}} \pm 0.24$ \\
\hline & GST U/ml & $14.92 \pm 2.64$ & $24.58^{a} \pm 4.67$ & $16.00 \pm 2.14$ & $16.91^{\mathrm{b}} \pm 2.24$ \\
\hline & GPx (U/ml) & $176.25 \pm 30.29$ & $160.88 \pm 17.05$ & $177.03 \pm 20.06$ & $167.61 \pm 22.19$ \\
\hline & $\mathrm{GR}(\mathrm{U} / \mathrm{ml})$ & $2.41 \pm 0.56$ & $2.13 \pm 0.48$ & $2.24 \pm 0.55$ & $2.35 \pm 0.51$ \\
\hline & SOD (U/ml) & $2105.46 \pm 90.08$ & $2079.21 \pm 82.97$ & $2089.11 \pm 54.13$ & $2051.66 \pm 78.02$ \\
\hline & CAT (U/ml) & $232.91 \pm 32.91$ & $244.98 \pm 45.54$ & $238.70 \pm 37.74$ & $267.60 \pm 53.83$ \\
\hline \multirow{7}{*}{$\stackrel{\bar{\Phi}}{\stackrel{亠}{\Xi}}$} & GSH (mg/g) & $71.20 \pm 2.93$ & $67.63^{a} \pm 2.08$ & $70.34 \pm 1.45$ & $68.22 \pm 6.30$ \\
\hline & $\mathrm{MDA}(\mathrm{nmol} / \mathrm{g})$ & $41.01 \pm 5.78$ & $59.36^{a} \pm 5.56$ & $41.34 \pm 6.89$ & $48.05^{\mathrm{a}, \mathrm{b}} \pm 6.68$ \\
\hline & GST (U/g) & $84.47 \pm 8.37$ & $108.14^{\mathrm{a}} \pm 8.45$ & $76.17 \pm 7.33$ & $70.65^{a, b} \pm 5.22$ \\
\hline & GPx (U/g) & $141.55 \pm 15.80$ & $114.45^{\mathrm{a}} \pm 5.43$ & $127.87 \pm 16.73$ & $126.71^{\mathrm{b}} \pm 18.85$ \\
\hline & GR (U/g) & $35.42 \pm 2.02$ & $31.75^{\mathrm{a}} \pm 2.25$ & $35.55 \pm 3.19$ & $33.09 \pm 3.29$ \\
\hline & $\operatorname{SOD}(\mathrm{U} / \mathrm{g})$ & $2019.87 \pm 73.67$ & $1983.59 \pm 761.36$ & $1888.81^{\mathrm{a}} \pm 50.45$ & $2006.37 \pm 43.14$ \\
\hline & CAT (U/g) & $336.51 \pm 34.70$ & $397.56^{a} \pm 57.60$ & $338.74 \pm 33.35$ & $322.36^{b} \pm 42.58$ \\
\hline \multirow{7}{*}{$\frac{\frac{c}{\sqrt[N]{n}}}{\infty}$} & $\mathrm{GSH}(\mathrm{mg} / \mathrm{g})$ & $18.28 \pm 1.63$ & $19.66 \pm 3.67$ & $18.14 \pm 4.29$ & $19.94 \pm 3.03$ \\
\hline & MDA (nmol/g) & $39.28 \pm 4.17$ & $70.91^{\mathrm{a}} \pm 8.51$ & $39.50 \pm 4.75$ & $37.69^{\mathrm{b}} \pm 6.09$ \\
\hline & GST (U/g) & $57.23 \pm 10.24$ & $72.95^{a} \pm 11.35$ & $56.10 \pm 5.95$ & $57.79^{b} \pm 5.66$ \\
\hline & GPx( U/g) & $163.57 \pm 30.46$ & $154.79 \pm 21.86$ & $165.37 \pm 36.19$ & $160.81 \pm 17.51$ \\
\hline & GR (U/g) & $32.83 \pm 0.33$ & $29.09^{a} \pm 3.17$ & $33.07 \pm 2.22$ & $31.47 \pm 2.83$ \\
\hline & $\operatorname{SOD}(\mathrm{U} / \mathrm{g})$ & $2165.24 \pm 47.09$ & $2161.02 \pm 32.72$ & $2114.92 \pm 69.27$ & $2117.61^{a, b} \pm 22.54$ \\
\hline & CAT (U/g) & $2.16 \pm 0.61$ & $6.21^{a} \pm 1 .{ }^{3} 6$ & $2.65 \pm 0.50$ & $2.58^{\mathrm{b}} \pm 0.41$ \\
\hline \multirow{7}{*}{ 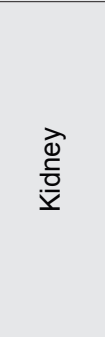 } & $\mathrm{GSH}(\mathrm{mg} / \mathrm{g})$ & $70.52 \pm 1.77$ & $59.10^{a} \pm 2.89$ & $65.40^{\mathrm{a}} \pm 4.87$ & $63.45^{\mathrm{a}} \pm 6.97$ \\
\hline & $\mathrm{MDA}(\mathrm{nmol} / \mathrm{g})$ & $115.06 \pm 10.86$ & $151.76^{a} \pm 12.32$ & $118.94 \pm 15.29$ & $158.28^{\mathrm{a}} \pm 23.00$ \\
\hline & GST (U/g) & $38.53 \pm 4.64$ & $61.40^{\mathrm{a}} \pm 7.17$ & $40.27 \pm 6.27$ & $52.61^{\mathrm{a}, \mathrm{b}} \pm 4.58$ \\
\hline & GPx (U/g) & $157.70 \pm 12.05$ & $145.07 \pm 18.72$ & $152.99 \pm 32.95$ & $149.70 \pm 24.63$ \\
\hline & $\mathrm{GR}(\mathrm{U} / \mathrm{g})$ & $53.21 \pm 4.33$ & $46.38^{\mathrm{a}} \pm 3.30$ & $52.46 \pm 1.49$ & $51.76^{b} \pm 2.27$ \\
\hline & $\mathrm{SOD}(\mathrm{U} / \mathrm{g})$ & $2147.03 \pm 44.03$ & $2100.49 \pm 40.82$ & $2145.76 \pm 28.33$ & $2146.31 \pm 54.73$ \\
\hline & CAT (U/g) & $269.69 \pm 48.16$ & $308.78 \pm 50.29$ & $285.32 \pm 21.75$ & $296.49 \pm 57.39$ \\
\hline \multirow{7}{*}{$\begin{array}{l}\frac{c}{\Phi} \\
\frac{0}{0} \\
\text { ஸे }\end{array}$} & GSH (mg/g) & $72.75 \pm 2.54$ & $73.98 \pm 1.55$ & $69.63 \pm 3.59$ & $73.44 \pm 0.69$ \\
\hline & $\mathrm{MDA}(\mathrm{nmol} / \mathrm{g})$ & $158.67 \pm 25.60$ & $199.90^{\mathrm{a}} \pm 14.15$ & $159.96 \pm 17.88$ & $153.87^{b} \pm 19.73$ \\
\hline & GST (U/g) & $34.68 \pm 3.99$ & $47.20^{\mathrm{a}} \pm 6.38$ & $37.43 \pm 4.55$ & $36.67^{\mathrm{b}} \pm 5.64$ \\
\hline & GPx( U/g) & $151.20 \pm 16.11$ & $143.42 \pm 11.04$ & $150.00 \pm 33.60$ & $145.67 \pm 26.61$ \\
\hline & GR (U/g) & $12.10 \pm 0.60$ & $12.94 \pm 2.37$ & $11.96 \pm 1.63$ & $12.06 \pm 0.68$ \\
\hline & $\mathrm{SOD}(\mathrm{U} / \mathrm{g})$ & $2258.75 \pm 63.55$ & $2179.14^{a} \pm 56.44$ & $2218.86 \pm 43.06$ & $2239.09^{b} \pm 26.95$ \\
\hline & CAT (U/g) & $20.28 \pm 1.39$ & $34.43^{a} \pm 8.95$ & $21.86 \pm 1.67$ & $22.05^{b} \pm 1.32$ \\
\hline
\end{tabular}

Each value is the mean $\pm S D$ of 6 animals per group (One way ANOVA).

a: Significantly different from control group.

b: Significantly different from $\mathrm{CCl}_{4}$ group. 


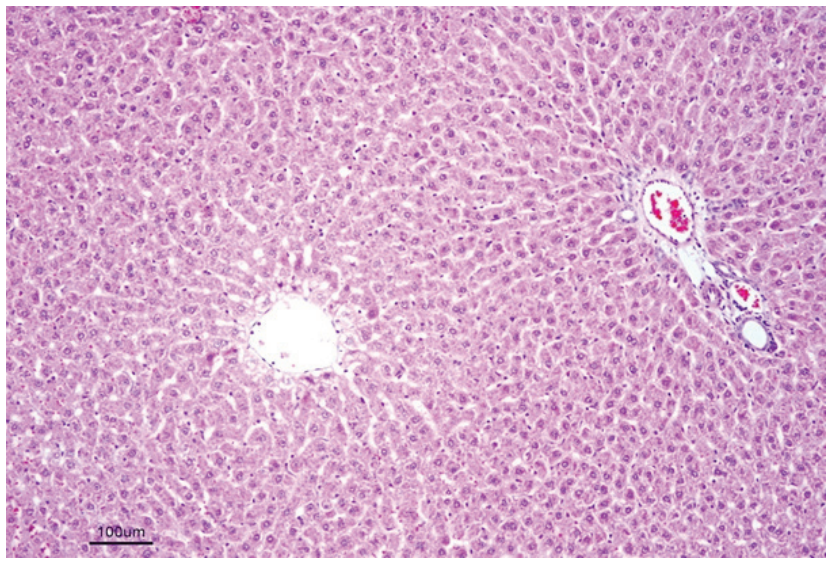

Figure 1: (control group): The liver of control group rats shows normal architecture of lobules (haematoxylin-eosin, Bar $=100 \mu$ )

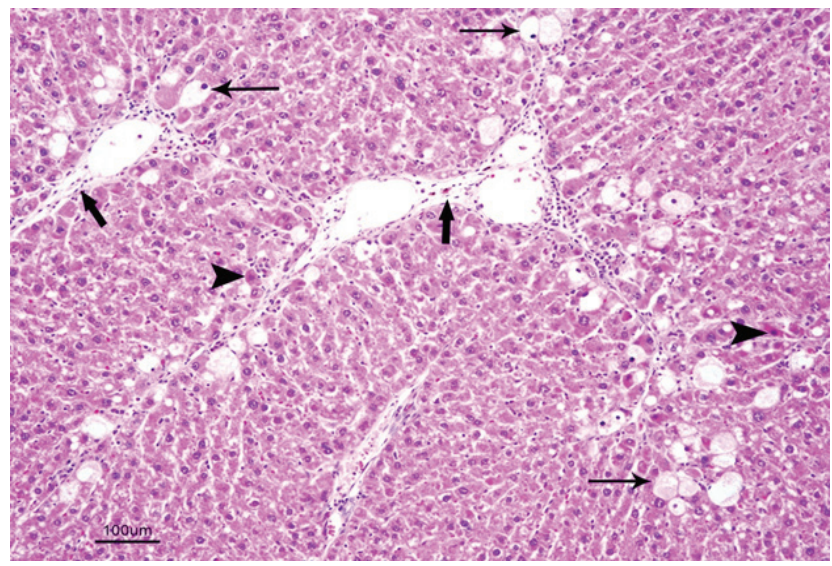

Figure 2: ( $\mathrm{CCl}_{4}$-treated group): Hydropic degeneration (fine arrows) and coagulation necrosis (arrow heads) in the hepatocytes, and fibrous bands extending from periacinar regions to parenchyma. (Haematoxylin-eosin, Bar= $100 \mu$ )

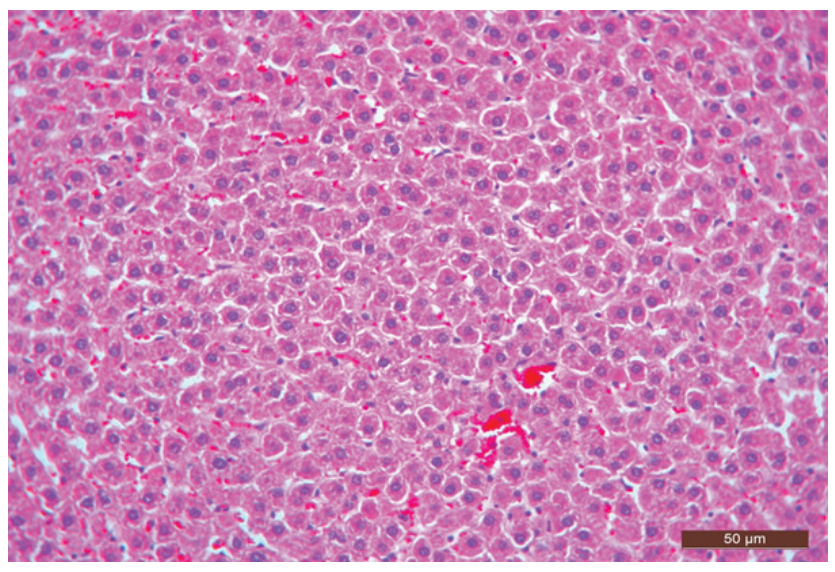

Figure 3: (CP-treated group): The liver of $10 \%$ dried fig group rats shows normal architecture of lobules (haematoxylin-eosin, Bar $=100 \mu$ )

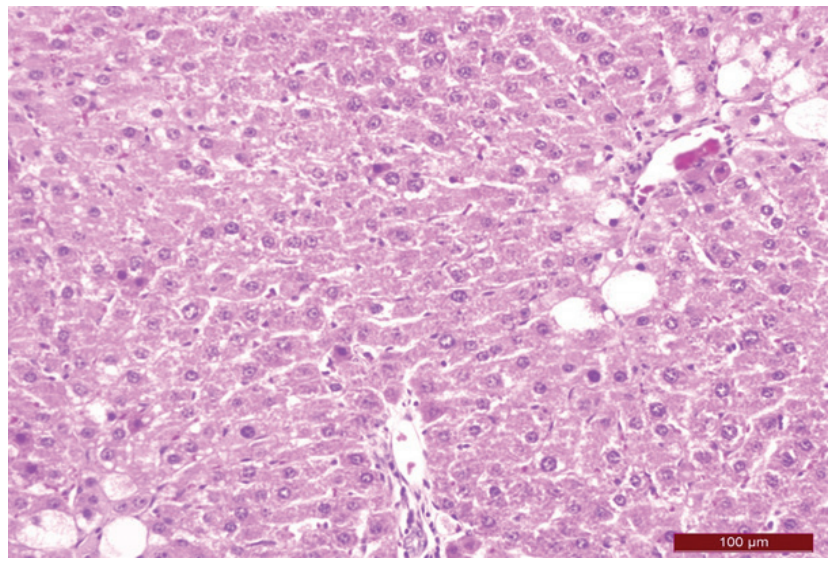

Figure 4: $\left(\mathrm{CP}+\mathrm{CCl}_{4}\right.$-treated group): Note that there is no hydropic degeneration and coagulation necrosis in the hepatocytes, and fibrosis. (Haematoxylin-eosin, Bar $=100 \mu$ )

\section{DISCUSSIONS}

Today, the world of natural products rather than synthetic drugs continues to seek to use the power of treatment. Replace synthetic food additives with natural antioxidants are also increasing their efforts to change. Functional foods through their specific components or prophylactic or therapeutic effect are. Numerous studies have demonstrated that a great number of medicinal and aromatic herbs, as well as fruits and leaves of some berry plants, biosynthesis phytochemicals possessing antioxidant property and may be used as a natural source of free radical scavenging compounds. ${ }^{24,25}$ Therefore, studies are needed to provide effective protection from the damaging agents and experimental studies have implicated the influence of a functional plant, $\mathrm{CP}$ in this regard. The first aim of this study was to investigate whether the $\mathrm{CP}$ supplementation could prevent $\mathrm{CCl}_{4}$ toxic damages on the liver and kidney, decrease content of the MDA and efficacy on the antioxidant defense system and histopatholgical changes of liver in rats.

The results showed that $\mathrm{CCl}_{4}$ caused a significant increase in the AST, ALT, GGT, and LDH levels in comparison to those of control rats whereas CP supplementation caused a significant decrease in these serum marker enzymes in comparison to those of $\mathrm{CCl}_{4}$ treated rats. The reasons for such effect of $\mathrm{CCl}_{4}$ and the $\mathrm{CP}$ supplementation were not certainly understood at present. However, it is known that several soluble enzymes in blood serum have been considered as indicators of the hepatic dysfunction and damage. Further, ALT and AST levels are also of value indicating the existence of liver diseases, as this enzyme is present in large quantities in the liver. ALT increases in serum 
when cellular degeneration or destruction occurs in this organ. ${ }^{26}$ The increase in plasma $\mathrm{LDH}$ activity may be due to the hepatocellular necrosis leading to leakage of the enzyme to the blood stream. ${ }^{27}$ Thus, when $\mathrm{CCl}_{4}$ may lead to the release of these enzymes into plasma because of autolytic breakdown or cellular necrosis, the $\mathrm{CP}$ supplement imparts protection against $\mathrm{CCl}_{4}$ induced oxidative injury that may result in development of liver damage.

As shown in the Table 2, the present study demonstrated that the CP could have antioxidative role in rats. This was obvious from our observation that, by the consequence of additional CP treatment in vivo as the concentration of MDA in the tissues differed from that of $\mathrm{CCl}_{4}$-exposed group. According to the obtained results, while MDA concentrations increased in the erythrocytes, liver, brain, kidney and spleen of rats treated with $\mathrm{CCl}_{4}$, the MDA contents of the tissue significantly decreases in the $\mathrm{CP}$ supplementation group compared to that of $\mathrm{CCl}_{4}$ group. The reasons for such effect of $\mathrm{CCl}_{4}$ and the $\mathrm{CP}$ additions are not understood at the present. Nevertheless, the increased MDA content might have resulted from an increase of ROS as a result of stress condition in the rats with $\mathrm{CCl}_{4}$ intoxication. Studies have shown that $\mathrm{CCl}_{4}$ is potent liver toxicant and cause severe damage in vital organs like liver. ${ }^{28,29}$ The excessive generation of free radicals in $\mathrm{CCl}_{4}$ induced liver damage will provokes a massive increase of lipid peroxidation in liver. ${ }^{30}$ On the other hand, it is known that the elevation of lipid peroxidation after the consumption of some xenobiotics and following superoxide over production that produce dismutation singlet oxygen and $\mathrm{H}_{2} \mathrm{O}_{2}$, can be easily converted later into the reactive $\mathrm{OH}$. Both single oxygen and $\mathrm{OH}$ radicals have a high potential to initiate free radicals chain reactions of lipid peroxidation. Further, it is known that ${ }^{\circ} \mathrm{OH}$ can initiate lipid peroxidation in tissues and MDA is a major oxidating product of peroxidized polyunsaturated fatty acids. ${ }^{31}$ Increased MDA content is an important indicator of lipid peroxidation. ${ }^{32}$ Meanwhile, SOD, GR, GPX GST and CAT activities and GSH levels were fluctuated at significant levels in the $\mathrm{CCl}_{4}$-treated, generally as an increase whereas the administration of CP supplementation restored the $\mathrm{CCl}_{4}$ induced imbalance between the fluctuated antioxidant system to near normal levels, particularly in erythrocytes, liver, brain, kidney and spleen. The reasons for such effect of functions of plant supplementation are not understood at the present. However, oxidative stress can affect the activities of protective enzymatic antioxidants in organisms exposed to $\mathrm{CCl}_{4}$. The fluctuated ADS activities may reflect an adaptive change against $\mathrm{CCl}_{4}$-induced $\mathrm{ROS}$ toxicity. ${ }^{30}$
However, the increased activities of ASD are known to serve as protective responses to eliminate xenobiotics. ${ }^{33}$ Thus, the existence of an inducible antioxidant system may reflect an adaptation of organisms. Also, the reasons for such effect of the CP addition may be due to antioxidant activity. CP supplementation treatment protected against lipid peroxidation and depletion of antioxidant enzyme activities. Previous studies have shown the riches of polyphenols in carob fruit. ${ }^{34,35}$

$\mathrm{CCl}_{4}$ induced rats showed severe and common degenerative and necrotic changes. The pathological findings, observed in cases of $\mathrm{CCl}_{4}$ toxicity are similar to previous reports. ${ }^{28,29,30}$ These results of our investigations are in accordance with those of ${ }^{28,29,30}$ who have reported that the $\mathrm{CCl}_{4}$-induced hepatotoxicity and the potent effect of $\mathrm{CCl}_{4}$ on the excessive generation of free radicals in $\mathrm{CCl}_{4}$ induced liver damage will provoke a massive increase of lipid peroxidation in liver. The pathological our findings, observed in cases of $\mathrm{CCl}_{4}$, are similar to the previous reports. CP treated rats did not showed significantly less histological abnormalities including hydropic degeneration, bile-duct proliferation and periportal fibrosis as compared with $\mathrm{CCl}_{4}$-treated rats. Thereby, $\mathrm{CP}$ protective role in countering the hepatotoxicity induced by $\mathrm{CCl}_{4}$ is arises. So far, no study examining the preventive role of $\mathrm{CP}$ supplemented food in vivo has been made on rat histological abnormalities, serum biomarkers, antioxidant defense systems and MDA content as a containing diet supplementation. Therefore, we had no chance to compare our results with the previous ones.

\section{CONCLUSION}

In conclusion, this study demonstrated that $\mathrm{CCl}_{4}$ exposure gave rise to lipid peroxidation via inducing the ROS and had different effects on various tissues of rats on their antioxidant defense enzymes systems. This can result from adaptation of different qualities of cell physiology for different tissues. According to the data obtained by the survey of CP tissues of the liver, it can be concluded that there is a protective feature, and has antioxidant activity. CP has protective effects on liver, but to understand the molecular mechanism and nature of this process better and to reach a conclusion more studies are needed. The protective and anti-oxidant effect of $\mathrm{CP}$ on liver need to be studied more on the rats in vivo.

\section{ACKNOWLEDGEMENT}

None of the authors has a commercial interest, financial interest, and/or other relationship with manufacturers of pharmaceuticals, laboratory supplies, and/or medical devices or with commercial providers of medically 
related services. The authors would like to thank Prof. Dr. Zabit YENER, Department of Pathology, Faculty of Veterinary, University of Yuzuncu Yil, Van, Turkey for his help in the histopathological section.

\section{FUNDING}

The authors are grateful to the Mugla Sitk1 Kocman University Grant Commission for providing financial assistance during the tenure of research numbered with MSKU-BAP-2013-65.

\section{AVAILABILITY OF DATA AND MATERIALS}

Data are all contained within the paper.

\section{AUTHORS' CONTRIBUTIONS}

HS: designed the study and performed all the experiments. AD: designed the study and analyzed data. IC: analyzed data wrote the manuscript and supervised the study. All authors read and approved the final manuscript.

\section{CONFLICT OF INTEREST}

The authors declare that they have no competing interests.

\section{ETHICS APPROVAL AND CONSENT TO PARTICIPATE}

The ethic regulations have been followed in accordance with The National and Institutional guidelines for the protection of animal welfare during experiments. Ethical approval was obtained from the Animal Experiments Local Ethics Committee of Yuzuncu Yil University.

\section{ABBREVIATIONS USED}

$\mathbf{C C l}_{4}$ : Carbontetrachloride; $\mathbf{C P}$ : Carobpods;AST: Aspartate aminotransferase; ALT: Alanin aminotransferase; GGT: Gamma glutamyl transpeptidase; LDH: Lactate dehydrogenase;TP:Totalproteine;TC:Total cholesterol; ADS: Antioxidant defense systems; GSH: Reduced glutathione; GR: Glutathione reductase; SOD: Superoxide dismutase; GST: Glutathione $S$-transferase; CAT: catalase; GPx: glutathione peroxidase; MDA: Malondialdehyde.

\section{REFERENCES}

1. Temiz MA, Temur A, Celik I. Antioxidant role and hepatoprotective effects of carob (Ceratoniasiliqua I.) seeds against ethanol-induced oxidative stress in rats. J Food Nutr Res. 2015;3(1):57-61.

2. Griel AE, Kris-Etherton PM. Tree nuts and the lipid profile: a review of clinical studies Brit J Nutr. 2006;96:568-78. https://doi.org/10.1017/BJN20061866.
3. Oliveira AP, Valentão P, Pereira JA, et al. Ficus carica L.: Metabolic and biological screening. Food Chem Toxicol. 2009;47:2841-6. https://doi. org/10.1016/j.fct.2009.09.004 PMid:19747518.

4. Ayaz FA, Torun H, Glew RH, et al. Nutrient content of carob pod (Ceratonia siliqua L.) flour prepared commercially and domestically. Plant Foods Hum Nutr. 2009;64(4):286-92. https://doi.org/10.1007/s11130-009-0130-3 PMid:19763833.

5. Barracosa P, Osorio J,Cravador A. Evaluation of fruit and seed diversity and characterization of carob (Ceratonia siliqua L.) cultivars in Algarve region. Scientia Horticulturae. 2007;114:250-7. https://doi.org/10.1016/j. scienta.2007.06.024.

6. Batista MT, Amaral MT, Proença Da, et al. Carob fruits as source of natural oxidant. In: Proceedings of the Communication in Third International carob Symposium, Tavira, Portugal. 1996;19-23. PMid:9206350.

7. Sidina MM, El Hansali M, Wahid $N$, et al. Fruit and seed diversity of domesticated carob (Ceratoniasiliqua L.) in Morocco. Scientia Horticulturae. 2009;123:110-6. https://doi.org/10.1016/j.scienta.2009.07.009.

8. Custódio L, Escapa AL, Fernandes E, et al. Phytochemical profile, antioxidant and cytotoxic activities of the carob tree (Ceratonia siliqua L.) germ flour extracts. Plant Foods Hum Nutr. 2011;66(1):78-84. https://doi.org/10.1007/ s11130-011-0214-8 PMid:21399924.

9. Kumazawa S, Taniguchi M, Suzuki Y, et al. Antioxidant activity of polyphenols in carob pods. J Agric Food Chem. 2002;50(2):373-7. https://doi.org/10.1021/ jf010938r PMid:11782210.

10. Luthria D. Significance of sample preparation in developing analytical methodologies for accurate estimation of bioactive compounds in functional foods. J Sci Food Agricul. 2006;86:2266-72. https://doi.org/10.1002/ jsfa.2666.

11. Cherniack EP. Polyphenols: planting the seeds of treatment for the metabolic syndrome. Nutrition. 2001;27(6):617-23. https://doi.org/10.1016/j. nut.2010.10.013 PMid:21367579.

12. Klenow S, Glei M, Haber B, et al. Carob fibre compounds modulate parameters of cell growth differently in human HT29 colon adenocarcinoma cells than in LT97 colon adenoma cells. Food Chem Toxicol. 2008;46(4):1389-97. https:// doi.org/10.1016/j.fct.2007.09.003 PMid:17950517.

13. Kim SH, Cheon HJ, Yun N, et al. Protective effect of a mixture of Aloe vera and Silybummarianum against carbon tetrachloride-induced acute hepatotoxicity and liver fibrosis. J Pharmacol Sci. 2009;109(1):119-27. nhttps://doi.org/10.1254/jphs.08189FP PMid:19151545.

14. Celik I, Temur A, Isık I. Hepatoprotective role and antioxidant capacity of pomegranate (Punica granatum L.) flowers infusion against trichloroacetic acid-exposed in rats. Food Chem Toxicol. 2009;47(1):145-49. https://doi. org/10.1016/j.fct.2008.10.020 PMid:19022327.

15. Yurt B, Celik I. Hepatoprotective effect and antioxidant role of sun, sulphiteddried apricot (Prunus armeniaca L.) and its kernel against ethanol-induced oxidative stress in rats. Food Chem Toxicol. 2011;49(2):508-13. https://doi. org/10.1016/j.fct.2010.11.035 PMid:21115094.

16. Dogan A, Celik I. Hepatoprotective and antioxidant activities of grape seeds against ethanol-induced oxidative stress in rats. Br J Nutr. 2012;107:45-51. https://doi.org/10.1017/S0007114511002650 PMid:21733325.

17. Beutler E, Duron O, Kelly BM. Improved method for the determination of blood glutathione. J Lab Clin Med. 1963;61(5):882-8 PMid:13967893.

18. Mannervik B, Guthenberg C. Glutathione S-transferase (Human Plasenta). Method Enzymol. 1981;77:231-5. https://doi.org/10.1016/S00766879(81)77030-7.

19. Carlberg I, Mannervik B. Purification and characterization of the flavoenzyme glutathione reductase from rat live. J Biol Chem. 1975;250:5475-80. PMid:237922.

20. Paglia DE, Valentine WN. Studies on quantitative and qualitative characterization of erythrocyte glutathione peroxidase. J Lab Clin Med. 1967;70:158. PMid:6066618.

21. McCord JM, Fridovich I. Superoxide dismutase, An enzymatic function for erythrocuprein (hemocuprein). J Biol Chem. 1969;244:6049-53. PMid:5389100.

22. Aebi H. Catalase In Methods of Enzymatic Analysis (Bergemeyer, $\mathrm{H}$ U.,ed). Academic Press, New York-London. 1974; pp 673-84. https://doi. org/10.1016/B978-0-12-091302-2.50032-3. 
23. Ortatatli $\mathrm{M}$, Oguz $\mathrm{H}$, Hatipoglu $\mathrm{F}$, et al. Evaluation of pathological changes in broilers during chronic aflatoxin (50 and $100 \mathrm{ppb}$ ) and clinoptilolite exposure. Res Vet Sci. 2005;78:61-8. https://doi.org/10.1016/j.rvsc.2004.06.006 PMid:15500841

24. Sacchetti G, Maietti S, Muzzoli M, et al. Comparative evaluation of 11 essential oils of different origin as functional antioxidants, antiradicals and antimicrobials in foods. Food Chem. 2005;9:621-32. https://doi.org/10.1016/j. foodchem.2004.06.031.

25. Yu LL, Zhou KK, Parry J. Antioxidant properties of cold pressed black caraway, carrot, cranberry, and hemp seed oils. Food Chemistry. 2005;91:723-9. https://doi.org/10.1016/j.foodchem.2004.06.044

26. Hassoun EA, Stohs SJ. Comparative studies on oxidative stress as a mechanism for the fetotoxic of TCDD, endrin and lindane in C57BL/6J and DBA/2J mice. Teratology. 1995;51:186-92.

27. Wang $X$, Zhai W. Cellular and biochemical factors in bronchoalveolar lavage fluids of rats exposed to fenvalerate. ZhongguoYaolixue Yu DulixueZoghi. 1988;2:271-6

28. Recknagel RO. A new direction in the study of carbon tetrachloride hepatotoxicity. Life Sci. 1983;33(5):401-8. https://doi.org/10.1016/00243205(83)90787-7.

29. Turkdogan MK, Ozbek $\mathrm{H}$, Yener Z, et al. The role of Urtica dioica and Nigella sativa in the prevention of carbon tetrachloride induced hepatotoxicity in rats. Phytother Res. 2003;17:942-6. https://doi.org/10.1002/ptr.1266 PMid:13680830.

\section{PICTORIAL ABSTRACT}

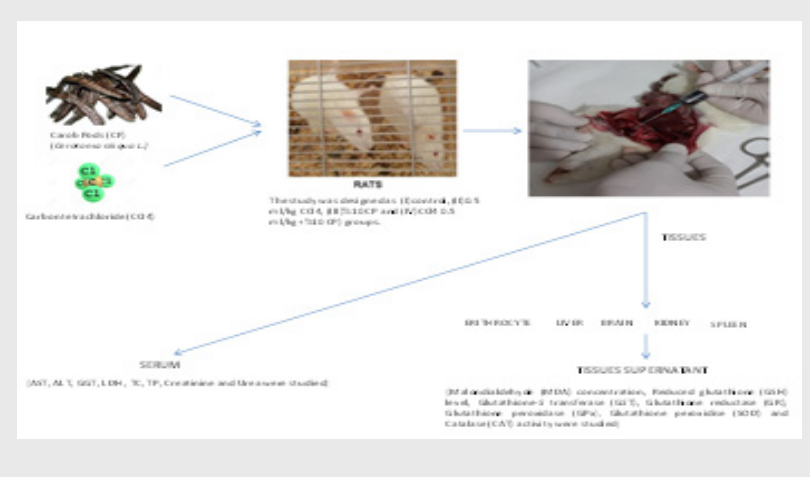

\section{About Authors}

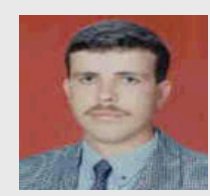

Dr Huseyin Suzek: He is presently working as Professor in Deparment of Nursing in Muğla Sitk1 Kocman University. He has experience in the area of pharmaceutical chemistry, the medicinal Plants, traditional medicine, toxicology and biochemistry. He has published a number of papers in his expertise area in various journals.

Dr İsmail Celik: He is presently working as Professor in Deparment of Molecular Biology and Genetic in Yuzuncu Yil University. At the same time he is also working as dean of education faculty in Yuzuncu Yil University. He has experience in the area of pharmaceutical chemistry, the medicinal Plants, traditional medicine, toxicology and biochemistry. He has published 90 ninety papers in his expertise area in various journals.

Abdulahad Dogan: He is presently working as Assistant Professor in Department of Biochemistry, Faculty of Pharmacy in Yuzuncu Yil University. He has experience in the area of pharmaceutical chemistry, molecular biochemistry. He has published a number of papers in his expertise area in various journals.

Cite this article: Suzek H, Celik I, Dogan A. Nephroprotective Hepatoprotective Potential and Antioxidant Role of Carob Pods (Cerotonia siliqua I.) against Carbon Tetrachloride-induced Toxicity in Rats. Indian J of Pharmaceutical Education and Research. 2017;51(2):312-20. 